\title{
Recognising and Rewarding Teaching Excellence: an argument for authentic metrics
}

Sally Brown

Who could argue with the basic premise of recognising and rewarding teaching excellence in higher education as is being planned within the UK in 2017? It is, for many, unquestionably a good idea for teaching and research in universities to be given parity of esteem. Indeed, following the National Committee of Inquiry into Higher Education in 1997, Lord Dearing proposed the setting up of an organisation to do exactly that (Dearing, 1997), in the form of the Institute for Learning and Teaching in Higher Education (ILTHE), which subsequently became part of the Higher Education Academy. Working within the ILTHE, I was charged with the task of setting up, in 2000, the National Teaching Fellowship Scheme (NTFS) for England and Northern Ireland. Having first singled out the key features of teaching excellence, I set about putting into place a process by which to recognise and reward up to twenty university teachers a year those who demonstrated what international research and parallel schemes in Australia, Canada, the USA and other nations had identified as the characteristics of outstanding university teachers.

Though the scheme and its criteria have been refined over the lifetime of the awards, the focus from the outset was on individuals nominated by their universities as demonstrating evidence of transforming and enhancing the student learning experience and supporting colleagues within and beyond their own institution. Their reflective claims must provide evidence of ongoing CPD and must be based on significantly more than mere assertion: it is the responsibility of the institution to provide endorsements that support the applicants' veracity and credibility, and testify to their impact.

Nationally, we have therefore seventeen years of experience of a system which has wide acceptance and high credibility across the UK (Wales is now within the scheme and a number of National Teaching Fellows (NTFs) have relocated to Scottish universities), but the Teaching Excellence Framework has no plans to take account of the scheme. With a community of more than 750 NTFs nowadays, represented by the Association of National Teaching Fellows (ANTF) that I chair, we are a vibrant and proactive network, overtly committed to sharing good practice and disseminating innovation across the higher education learning and teaching community in the UK and beyond. 


\section{TEF Special Edition}

The ANTF contributed fully to the consultations in advance of the introduction of the TEF and we were particularly keen that any metrics used to recognise excellent teaching should be those which truly represented improvements to the student experience brought about by interactions between $\mathrm{HEI}$ teachers and students, rather than measures representing existing differences in the level of advantage in different university mission-groups. For example, if salaries on graduation are to be a metric, this clearly reflects existing advantage of university entrants, rather than any evident value added by the $\mathrm{HEI}$. Some other proxy metrics, for example, contact hours for students on site, we regard as being less useful than metrics that focus on how committed universities are to foregrounding and improving the student learning experience.

Preferred metrics for us would be the relative number of promotions to Reader or Professor on the basis of teaching expertise, rather than research alone, or the relative proportion of staff who have achieved external recognition for their teaching, as measured by HEA Fellowships at Associate, Fellow, Senior Fellow or Principal Fellow, (HEA 2012), or by SEDA Fellowships at Fellow or Senior Fellow level, or, indeed, National Teaching Fellowships. Since most UK universities offer initial training programmes (often year-long, part-time and credit-bearing) for academic and learning support staff new to teaching in higher education, a further metric could be the proportion of staff who have successfully completed such programmes and who additionally commit annually to CPD.

Several consultation responses, including ours, suggested that impact studies could be used for the TEF as they have been for the REF. There are extant hundreds of successful applications for National Teaching Fellowships, HEA Senior Fellowships and Principal Fellowships which could provide, without any further work, case studies of excellent teaching and leadership for use by HEls.

National Teaching Fellows are committed to fostering innovations in learning and teaching, disseminating good practice and ensuring that pedagogic change is soundly based on researchbased scholarship. We are well represented on the panel of TEF assessors and as a group are active in championing a TEF process that uses authentic metrics. We argue that these should genuinely and validly gauge the value added by universities to the student learning experience. University teaching is too important for it to be allowed to become a means of gaming the system. 


\section{TEF Special Edition}

\section{Reference list}

Dearing, R. (1997) Higher Education in the learning society. The Dearing Report. The National Committee of Enquiry into Higher Education.

HEA. (2012) UK Professional Standards Framework. Available at:

http://www.heacademy.ac.uk/professional-recognition (Accessed: 7 April 2017). 